\title{
Optimización del Contenido de Ácidos en Ensilados de Vísceras de Tilapia Roja (Oreochromis spp.) con Análisis del Ciclo de Vida de los Alimentos Derivados
}

\author{
Lina M. Suarez, Julio R. Montes y José E. Zapata* \\ Grupo de Nutrición y Tecnología de Alimentos, Universidad de Antioquia UdeA, Calle 67 № 52-21, Medellín \\ - Colombia (e-mail: linam.suarez@udea.edu.co; jrma02@gmail.com; edgar.zapata@udea.edu.co) \\ ${ }^{*}$ Autor a quien debe ser enviada la correspondencia
}

Recibido Abr. 6, 2018; Aceptado Jun. 4, 2018; Versión final Jul. 23, 2018, Publicado Dic. 2018

\begin{abstract}
Resumen
El objetivo del presente trabajo fue optimizar el contenido de ácidos y las proporciones de ensilado en dietas para peces elaboradas con ensilados de vísceras de tilapia roja (Oreochromis spp.). Además, se evalúa el impacto ambiental de la obtención dichos dietas, por medio del Análisis del Ciclo de Vida. Se evaluó el efecto de la concentración de ácido sulfúrico y ácido fórmico y sobre los recuentos de mesófilos aerobios (ufc/g), hongos, levaduras (ufc/g), coliformes totales y fecales (NMP/g). Por otro lado, se evalúo el contenido de pienso vegetal y ensilado químico desengrasado sobre propiedades como flotabilidad, índice de adsorción de agua y densidad específica. Los resultados mostraron que es posible reducir la concentración de ácidos en el ensilado, sin comprometer su calidad microbiológica. En cuanto al impacto ambiental, la preparación de las dietas es la etapa que menos aportó a la emisión de gases de efecto invernadero $(5,6 \%)$ y consumo de energía $(1,8 \%)$, mientras que el secado de las dietas aportó el mayor impacto, con un $84 \%$ de la energía y un $50 \%$ de las emisiones de gases de efecto invernadero.
\end{abstract}

Palabras clave: análisis de ciclo de vida; ensilaje químico; impactos ambientales; vísceras de tilapia roja.

\section{Optimization Acid Content in Silage Viscera Red Tilapia (Oreochromis spp.) with Life Cycle Assessment of Feeds Derived}

\begin{abstract}
The aim of the present work was to optimize the acid content and the proportions of silage in fish diets elaborated with silage of viscera of red tilapia (Oreochromis spp.). In addition, the environmental impact of obtaining such diets was evaluated through Life Cycle Assessment. The effect of the concentration of sulfuric acid and formic acid (FA) and on the counts of aerobic mesophiles (cfu / g), fungi, yeast (cfu / g), total and fecal coliforms (NMP/g) was evaluated. On the other hand, the content of vegetable feed and degreased chemical silage on properties such as buoyancy, water adsorption index and specific density were evaluated. The results showed that it is possible to reduce the acid concentration in silage, without compromising its microbiological quality. Regarding the environmental impact, the preparation of diets is the stage that least contributes to the emission of greenhouse gases $(5.6 \%)$ and energy consumption (1.8\%), while the drying of diets provided the greatest impact, with $84 \%$ of energy and $50 \%$ of greenhouse gas emissions.
\end{abstract}

Keywords: life cycle assessment; chemical silage; environmental impacts; viscera of red tilapia. 


\section{INTRODUCCIÓN}

Hoy en día, el ser humano ha alcanzado un entendimiento avanzado a cerca de los beneficios sobre la salud, que se asocian al consumo de pescado. Esto ha conllevado a que la producción acuícola este en permanente crecimiento en todo el mundo. Es así como en el 2012, la producción piscícola global llegó a los 158 millones ton, de las cuales el $86 \%$ se destinó al consumo humano directo. En ese mismos año, en Colombia el sector de la acuicultura presentó un crecimiento en la producción del $9 \%$, siendo la tilapia roja la que más aporta con el $62 \%$, seguida de cachama blanca $16 \%$, tilapia plateada $14 \%$, trucha $5 \%$ y $3 \%$ las especies restantes (Esquivel et al., 2014). Este crecimiento va acompañado de un volumen de residuos equivalente, que pueden generar impactos ambientales de importancia, dado que representan entre $60-70 \%(\mathrm{w} / \mathrm{w})$ del total de la producción (Martínez-Alvarez et al., 2015; Saadi et al., 2014). En el caso de la tilapia roja (Oreochromis spp.), tan solo el 33\% del pez es comercialmente disponible (Minh, 2014). Estos residuos se componen principalmente de restos de fileteo (15-20\%), piel y aletas (1-3\%), huesos (9-15\%), cabezas $(9-12 \%)$, vísceras (12-18\%) y escamas (5\%) (Martínez-Alvarez et al., 2015), los cuales a pesar de ser importantes fuentes de proteínas, la mayoría de las veces son descartados sin ningún intento de recuperación. Por su riqueza en nutrientes, su inadecuado vertimiento puede afectar diferentes niveles de los ecosistemas, ocasionando problemas como reducción de la biomasa, de la densidad y diversidad de bentos y plancton, además de la modificación de las redes tróficas naturales (Saadi et al., 2014), sin embargo estos residuos pueden ser utilizados para alimentación animal, para la obtención de harina de pescado o fertilizantes, entre otros usos (Chalamaiah et al., 2012; Deraz, 2014).

Una de las alternativas de mayor utilización para la recuperación de nutrientes de los subproductos piscícolas, lo representa el ensilaje (Chalamaiah et al., 2012), que consiste en adicionar ácidos, enzimas o bacterias acido-lácticas, al pescado crudo o partes de él, para provocar el descenso del pH y la licuefacción de la masa por efecto de las enzimas endógenas, las cuales actúan a condiciones ácidas (Fernández et al., 2013). El producto obtenido es semilíquido pastoso, color pardo grisáceo, olor característico a pescado. Este producto aporta proteínas parcialmente hidrolizadas, con propiedades nutricionales muy similares a las del pescado de donde proceden (Botello et al., 2010), por lo que podrían mejorar la digestibilidad de las dietas en alimentación animal, que es uno de los factores que influyen positivamente sobre el crecimiento. En el caso de las proteínas y lípidos del ensilado de desecho de tilapia, se ha encontrado que tienen un perfil nutricional adecuado para especies herbívoras y omnívoras principalmente que pueden utilizarse como suplemento parcial de la harina de pescado (Güllü et al., 2014; Goosen et al., 2014), que es la fuente de proteínas más utilizada en alimentación animal, justamente por su digestibilidad y contenido proteico (Chalamaiah et al., 2012).

En comparación con la harina de pescado, el ensilaje tiene como ventajas que el proceso es virtualmente independiente de la escala, la tecnología es simple, los controles del proceso no son complejos, la inversión inicial es pequeña incluso a gran escala, los efluentes son reducidos, el proceso es rápido en clima tropical y los productos pueden ser usados en el sitio (Chalamaiah et al., 2012). Sin embargo, existen también algunas desventajas, como pueden ser el espacio requerido cuando la producción es voluminosa, el efecto sobre los costos por transporte para su aprovechamiento en otro sitio o por procesos como el secado. Adicionalmente, el efecto negativo sobre la calidad de los ácidos grasos del pescado que pueden ejercer los ácidos usados en el ensilaje químico, entre los más usados están el sulfúrico y el fórmico (Toledo et al., 2007). Estos ácidos pueden modificar el contenido de aminoácidos (Vidotti et al., 2003), el perfil de ácidos grasos y el contenido de ácidos grasos insaturados. Incluso con un marcado efecto negativo sobre el contenido en ácido docosahexanoico (DHA) que hoy día es altamente valorado por sus propiedades profilácticas y terapéuticas en el tratamiento de diversas situaciones nutricionales y enfermedades, dado que estos ácidos grasos son los principales componentes de los fosfolípidos, los cuales a su vez son las principales moléculas en la mayoría de las membranas biológicas. En este sentido, es importante tener en cuenta que las vísceras de pescado suponen entre un 7,5 -15\% del peso corporal del animal y tienen un alto contenido de ácidos grasos esenciales polinsaturados como ácido docosahexaenoico (DHA) y ácido eicosapentaenoico (EPA).

El contenido de ácido sulfúrico y fórmico en los ensilados químicos de subproductos de pescado ha sido usado en cierta forma como un paradigma, en el rango de 1.5-2\%, para cada ácido (Vidotti et al., 2003). Sin embargo, no se ha evaluado a profundidad cual sería el efecto sobre la microbiología del ensilado si se modifican los niveles de dichos ácidos, ni tampoco se ha profundizado en el efecto sobre el medio ambiente, al utilizarlos. A pesar de los reportes de literatura sobre las ventajas nutricionales del ensilaje, se requiere profundizar en los impactos ambientales de su práctica, ya que varias formas de energía son utilizadas para su obtención (Ogino et al., 2007). Una de las estrategias para tal fin lo representa el ACV, este es un método utilizado para evaluar los impactos medioambientales potenciales durante la vida de un producto o servicio (Henriksson et al., 2012; Papatryphon et al., 2004). El ACV implica el análisis de todas las diferentes fases que son requeridas o causadas por la existencia de un producto, incluyendo la materia prima y la energía de producción, manufactura, transporte y uso (d'Orbcastel et al., 2009), el cual se ha aplicado a diferentes sistemas en acuacultura (Pelletier et al., 2009), incluyendo la producción de dietas para peces (Smárason et 
al., 2017; Ytrestøyl et al., 2015). El objetivo del presente trabajo fue optimizar el contenido de ácidos en los ensilados y las proporciones de EQV/PV en dietas para peces elaboradas con ensilados de vísceras de tilapia roja (Oreochromis spp.). Además aplicar el ACV para evaluar el impacto ambiental del proceso de obtención de alimentos para peces utilizando los ensilados cuya concentración de ácidos y proporción EQV/PV fue optimizada.

\section{MATERIALES Y MÉTODOS}

La metodología presenta la elaboración del ensilaje, los análisis microbiológicos y fisicoquímicos, la formulación del alimento y el análisis de ciclo de vida.

\section{Manejo del sustrato}

Las vísceras de tilapia (VT) fueron suministradas por la piscícola El Gaitero, en San Jerónimo - Colombia, $\left(6^{\circ} 27^{\prime} 45.0^{\prime \prime} \mathrm{N} 75^{\circ} 46^{\prime} 43.2^{\prime \prime} \mathrm{W}\right)$, se transportaron refrigeradas hasta el laboratorio, donde se redujeron de tamaño en un procesador de alimentos (Black \& Decker, USA), para ser almacenados a $-20^{\circ} \mathrm{C}$ hasta su uso. Se realizarón análisis microbiológicos y se determinó el contenido de humedad, grasa, cenizas y proteína total ( $\mathrm{N} \times 6.25)$, mediante los métodos descritos en la AOAC (2000). Todos los reactivos usados fueron de grado analítico.

\section{Ensilaje químico de las vísceras de pescado}

Para la elaboración de los ensilajes, se tomaron $500 \mathrm{~g}$ de vísceras homogenizadas, se adicionaron en un recipiente de polietileno con la cantidad de ácido definida por el diseño experimental, fueron sellados herméticamente y almacenados a temperatura ambiente (alrededor de $25^{\circ} \mathrm{C}$ ) durante 30 días. Una vez pasado este tiempo el ensilaje es desengrasado por centrifugación por 6 minutos a $3000 \mathrm{rpm}$, para evitar que el producto final tenga exceso de grasa. Se desarrollaron 10 corridas experimentales según diseño de experimentos factorial central compuesto (Tabla 3), para evaluar el efecto de los factores: \% de ácido sulfúrico (AS) y \% de ácido fórmico (AF) sobre las respuestas: mesófilos aerobios (MA, ufc/g), hongos y levaduras (HML, ufc/g), coliformes totales (CT, NMP/g), coliformes fecales (CF, NMP/g) y $\mathrm{pH}$. Las cuales fueron evaluadas al inicio y pasado 30 días del ensayo de ensilaje. Los niveles de los factores utilizados fueron $0-$ $2 \%$ para ambos ácidos.

\section{Análisis microbiológicos}

El análisis de mesófilos aerobios, hogos y levaduras fue realizado empleando el agar Plate count (OXOID LTD, Inglaterra) y agar OGYE base según ISO (Merck KGaA, Alemania), respectivamente. El número más probable (NMP) de coliformes totales y fecales fue determinado con la técnica de tubos múltiples con caldo LMX modificado según MANAFI y OSSMER (Merck KGaA, Alemania).

\section{Análisis fisicoquímico}

Todos los análisis fisicoquímicos fueron analizados por triplicado siguiendo los métodos establecido por la AOAC (2000). La Humedad fue determinada en estufa de aire. El contenido de nitrógeno fue determinado por el método de kjeldahl $(F=6,25)$. El extracto etéreo fue determinado usando un montaje soxhlet. Las cenizas fueron analizadas por incineración y el pH fue medido con un potenciómetro (HORIBA, Japón).

\section{Formulación de alimento balanceado para tilapia roja (Oreochromis spp.)}

Para la elaboración de los alimentos se usó una mezcla de ensilaje de vísceras y pienso vegetal. El ensilaje se elaboró con las concentraciones de los ácidos que se definieron en el primer diseño experimental. El pienso vegetal estaba conformado por harina de soya $(58,33 \%)$, harina de maíz (12,91\%), salvado de trigo $(24,84 \%)$, aceite de soya $(1 \%)$, sal común $(0,42 \%)$ y fosfato de calcio $(2,5 \%)$. Todos los ingredientes se mezclaron y molieron en un molino de carne manual con un disco de $5 \mathrm{~mm}$, se secó por 17 horas a $60{ }^{\circ} \mathrm{C}$, en estufa de aire convectivo; finalmente se almacenó en bolsas de polietileno. Para optimizar las formulaciones se usó un diseño de mezclas de dos factores (Montgomery, 2000), pienso vegetal (PV) y ensilado químico desengrasado (EQD), ambos factores en niveles entre 0,4 y 0,6. Las variables respuestas fueron flotabilidad (F), índice de absorción de agua (IAA) y densidad específica (DE).

Índice de absorción de agua (IAA)

Se pusieron $5 \mathrm{~g}$ del alimento en $500 \mathrm{~mL}$ de agua con agitación $(70 \mathrm{rpm}$ ) por $5 \mathrm{~min}$, se filtró y pesó en sobrenadante. Según el método propuesto por Ainsworth et al., 2007 con algunas modificaciones. 


\section{Densidad específica (DE) y Flotabilidad ( $F)$}

Estas dos propiedades se midieron como lo describe Ma et al., (2012), con algunas modificaciones. Para flotabilidad se deposita un número determinado de pellets en un beaker con $400 \mathrm{ml}$ de agua y se establece el porcentaje que permanecen flotando después de un tiempo definido. Mientras que la densidad se determinó como la relación de la masa dividida por su volumen.

\section{Diseños experimentales}

Se realizaron dos diseños experimentales, el primero para definir concentración de los ácidos que favorece la estabilidad microbiológica y de pH en el ensilaje. Para esto se realizó un diseño de experimentos central compuesto con la metodología de superficie de respuesta (Montgomery, 2000); los factores fueron \% de ácido sulfúrico (AS) y \% de ácido fórmico (AF) con nivel inferior de $0 \%$ y nivel superior de $2 \%$ para cada uno. Las variables respuestas fueron: Mesófilos aerobios (ufc/g, MA), hongos y levaduras (ufc/g, HML), coliformes totales (NMP/g, CT), coliformes fecales (NMP/g, CF) y pH. Para la optimización se minimizo las variables microbiológicas. El segundo diseño tuvo como objetivo definir la formulación del alimento para pescado, para esto se usó un diseño de mezclas de dos factores (Montgomery, 2000), pienso vegetal (PV) y ensilaje acido desengrasado por centrifuga por 6 minutos a $3000 \mathrm{rpm}$ (EQD) en un intervalo inferior de 0,4 y uno superior de 0,6 para cada uno; las variables respuestas fueron flotabilidad (F), índice de absorción de agua (IAA) y densidad especifica (DE). El pienso vegetal estaba conformado por harina de soya (58,33\%), harina de maíz $(12,91 \%)$, salvado de trigo $(24,84 \%)$, aceite de soya $(1 \%)$, sal común $(0,42)$ y fosfato de calcio $(2,5 \%)$.

Para ambos diseños se realizó el análisis de varianza (ANOVA) con un nivel de confianza del 95\%, el cual incluye la significancia estadística de cada uno de los términos del modelo ajustado (Valor -P), los efectos estimados en cada término y el coeficiente de determinación del modelo $\left(R^{2}\right)$ con el fin de establecer la exactitud del modelo para representar los datos. Se utilizó el software Design Expert Versión 8.0.6 (Stat-Ease, EE.UU).

\section{Análisis de Ciclo de Vida (ACV) del alimento}

Este análisis permite identificar los impactos ambientales potenciales y los puntos críticos de un proceso dado, el cual ha sido aplicado para evaluar el impacto de dietas en alimentación animal (Boissy et al., 2011). En este caso se aplicó a la elaboración de alimentos para peces utilizando ensilado químico de vísceras de tilapia roja como fuente de proteína. Para identificar estos impactos en las dietas con inclusión de ensilado químico de VT se definió $1 \mathrm{Kg}$ de alimento como unidad funcional (UF) del sistema. Los impactos se calcularon usando la metodología CML 2 Baseline 2000, desarrollada originalmente por el Centro de Estudios Ambientales de la Universidad de Leiden en Holanda (Smárason et al., 2017; Guinée et al., 2001), que es el método de evaluación de impacto más utilizado en los estudios de acuicultura de ACV (Henriksson et al., 2012). Los límites del sistema se muestran en la Tabla 1, y van desde la recolección de las vísceras (P1), la elaboración del ensilado químico (P2), la preparación de dietas (P3), hasta el secado del alimento (P4).

En este este estudio no se incluyen las etapas de producción y obtención de las materias primas vegetales, así como la etapa de cultivo de las tilapias rojas, debido a que la producción del alimento es la etapa con mayor impacto ambiental en la producción piscícola (Dekamin et al., 2015; Ytrestøyl et al., 2015; Samuel-Fitwi et al., 2013; Boissy et al., 2011), con un 87\% de la emisión de GEl (Smárason et al., 2017). El inventario de las entradas y salidas del sistema se presentan en la Tabla 1, los datos utilizados fueron recolectados en el sitio de estudio, de bases de datos e inventarios de software CCaLC2 (versión 1,7) y artículos de la literatura científica (Henriksson et al., 2012; Ogino et al, 2007). Dado que las vísceras son subproductos sin valor comercial, no se consideraron sus cargas ambientales. Para el cálculo de las emisiones de GEI del transporte de las vísceras se tuvo en cuenta el factor de emisión para un vehículo ligero con gasolina en un recorrido de tipo rural $\left(207,32 \mathrm{KgCO}_{2} / \mathrm{Km}\right)$ (CAIB, 2011), para el cálculo de emisiones asociadas al consumo eléctrico se utilizó el factor de emisión eléctrica de Colombia $\left(0,23 \mathrm{KgCO}_{2} / \mathrm{Km}\right)$, las demás emisiones de las materias primas y categorías de impacto de las actividades del sistema se determinaron con el software CCaLC2 (versión 1,700). Las categorías de impacto analizadas fueron emisiones de gases efecto invernadero (GEI) y potencial de calentamiento global, consumo de energía y de agua, potencial de eutrofización y potencial de acidificación, utilizando el mismo software.

\section{RESULTADOS Y DISCUSIÓN}

A continuación, se muestran los resultados obtenidos de la caracterización bromatológica, el efecto de la concentración de ácidos sobre la calidad microbiológica de los ensilados, la elaboración de alimento balanceado para tilapia en la fase de engorde y su análisis de Ciclo de Vida (ACV). 


\section{Caracterización bromatológica}

En la Tabla 2, se presentan las características bromatológicas de las vísceras de tilapia frescas (VT), ensilaje químico de vísceras de tilapia (EQ), ensilaje químico desengrasado (EQD) y alimento (A) elaborado a partir de ensilaje químico para tilapia en fase de engorde. En ella se observa que la composición de las vísceras está en el rango de valores típicos para esta especie.

Tabla 1: Inventario de entradas y salidas de la elaboración de alimentos con inclusión de ensilados químicos de vísceras de tilapia roja.

\begin{tabular}{lcc}
\hline \multicolumn{1}{c}{ Entradas/ Materia Prima } & Etapa & Alimento $(\mathrm{kg})$ \\
\hline VT & $\mathrm{P} 2$ & $9,87 \mathrm{E}-01$ \\
Ácido sulfúrico & $\mathrm{P} 2$ & $3,00 \mathrm{E}-05$ \\
Ácido fórmico & $\mathrm{P} 2$ & $1,20 \mathrm{E}-03$ \\
Sorbato de Potasio & $\mathrm{P} 2$ & $2,40 \mathrm{E}-04$ \\
BHT & $\mathrm{P} 2$ & $4,00 \mathrm{E}-06$ \\
$\mathrm{NaOH}$ & $\mathrm{P} 3$ & $6,46 \mathrm{E}-04$ \\
Almidón & $\mathrm{P} 3$ & $6,27 \mathrm{E}-03$ \\
Proteína de soya & $\mathrm{P} 3$ & $3,14 \mathrm{E}-03$ \\
Torta de soya & $\mathrm{P} 3$ & $5,38 \mathrm{E}-02$ \\
Agua & $\mathrm{P} 3$ & $2,50 \mathrm{E}+0$ \\
Material de empaque & & \\
Bolsas de PE & $\mathrm{P} 1$ & $8,66 \mathrm{E}-05$ \\
Balde PP & $\mathrm{P} 2$ & $2,39 \mathrm{E}-03$ \\
Bolsa de PP & $\mathrm{P} 4$ & $1,88 \mathrm{E}-04$ \\
Consumo de energía & & $\mathrm{kW} / \mathrm{h}$ \\
Electricidad (Desengrasado VT) & $\mathrm{P} 2$ & $2,41 \mathrm{E}-03$ \\
Electricidad (Procesamiento VDT) & $\mathrm{P} 2$ & $7,76 \mathrm{E}-03$ \\
Electricidad (Extrusión dieta) & $\mathrm{P} 3$ & $7,96 \mathrm{E}-02$ \\
Electricidad (Secado) & $\mathrm{P} 4$ & $7,92 \mathrm{E}-01$ \\
Transporte & & $\mathrm{km}$ \\
Recolección Vísceras & $\mathrm{P} 1$ & $1,08 \mathrm{E}-01$ \\
\hline Salidas & & $\mathrm{kg}$ \\
Dieta (UF) & & 1 \\
Residuos & & 2,5 \\
Efluente alcantarillado (L) & $\mathrm{P} 1$ & $6,14 \mathrm{E}-03$ \\
Residuos sólidos orgánicos (kg) & &
\end{tabular}

Tabla 2: Caracterización bromatológica de los diferentes sustratos.

\begin{tabular}{lcccc}
\hline Análisis & $V T$ & $E Q$ & $E Q D$ & $A$ \\
\hline$\% \mathrm{P}$ & 4,62 & 5,77 & 7,12 & 28,94 \\
$\% \mathrm{H}$ & 63,57 & 65,65 & 82,61 & 10,46 \\
$\% \mathrm{G}$ & 21,03 & 20,09 & 6,12 & 18,28 \\
$\% \mathrm{C}$ & 2,07 & 4,24 & 0,97 & 5,07 \\
Carbohidratos & 8,61 & 4,25 & 3,18 & 37,24 \\
\hline
\end{tabular}

\section{Efecto de la concentración de ácidos}

El efecto de la concentración de ácidos sobre la calidad microbiológica de los ensilados se evalúo a través del primer diseño experimental, del cual se presentan en la Tabla 3 los resultados de las corridas experimentales, en la Tabla 4 los resultados del análisis de varianza (ANOVA) y en las ecuaciones 1-5 los modelos matemáticos para cada una de las variables respuesta. Se aprecia que todos los modelos tienen significancia estadística y que los $\mathrm{R}^{2}$ presentan valores por encima de 0,99 en todos los casos excepto para el $\mathrm{pH}$, lo que indica que los modelos son adecuados para representar las respuestas en función de los factores. En las figuras 1 se presenta el comportamiento gráfico de las respuestas en función de las variables a partir de las ecuaciones 1-5. En ellas se observa que los recuentos microbiológicos decrecen a medida que se incrementan las concentraciones de los ácidos, lo cual es favorable para la conservación de los ensilados. Sin embargo, el incremento desmedido de la concentración de ácidos puede afectar negativamente el costo del proceso, además de los efectos 
negativos del $\mathrm{pH}$ extremadamente bajo pueda ocasionar sobre las características organolépticas del alimento obtenido y la necesidad de neutralización de los ensilados al finalizar el proceso.

Tabla 3: Matriz de experimentos para la elaboración de ensilaje químico con ácido sulfúrico y fórmico.

\begin{tabular}{cccccccc}
\hline \multirow{2}{*}{ Corridas } & $A S(\%)$ & $A F(\%)$ & $\begin{array}{c}M A(U F C / g) \\
\text { día } 30\end{array}$ & $\begin{array}{c}H M L(U F C / g) \\
\text { día } 30\end{array}$ & $\begin{array}{c}C T(N M P / g) \\
\text { día } 30\end{array}$ & $\begin{array}{c}C F(N M P / g) \\
\text { día } 30\end{array}$ & $\begin{array}{c}p H \\
\text { día } 30\end{array}$ \\
\hline 1 & 0 & 0 & $3,0 \times 10^{2}$ & $3,0 \times 10^{5}$ & 200 & 200 & 5,4 \\
2 & 2 & 0 & $<10$ & $<10$ & 4 & $<3$ & 1,2 \\
3 & 1 & 0 & $3,0 \times 10^{2}$ & $3,0 \times 10^{5}$ & $<3$ & $<3$ & 2,4 \\
4 & 1 & 1 & $<10$ & $<10$ & $<3$ & $<3$ & 2,3 \\
5 & 1 & 2,41 & $<10$ & $<10$ & 4 & $<3$ & 1,9 \\
6 & 1 & 1 & $<10$ & $<10$ & $<3$ & $<3$ & 2,2 \\
7 & 0 & 2 & $2,0 \times 10^{2}$ & $<10$ & $<3$ & $<3$ & 3,2 \\
8 & 2,41 & 1 & $<10$ & $<10$ & $<3$ & $<3$ & 0,9 \\
9 & 0 & 1 & $7,0 \times 10^{1}$ & $<10$ & 23 & 4 & 3,5 \\
10 & 2 & 2 & $<10$ & $<10$ & $<3$ & $<3$ & 1,1 \\
\hline
\end{tabular}

Tabla 4: ANOVA del diseño experimental para la proporción de ácido en la elaboración de ensilaje químico.

\begin{tabular}{cccccc}
\hline \multicolumn{5}{c}{ Valor $P$} \\
\hline Factor & MA (UFC/g) & $H M L(U F C / g)$ & $C T(N M P / g)$ & $C F(N M P / g)$ & $p H$ \\
Modelo & 0,023 & 0,008 & 0,002 & 0,002 & 0,001 \\
A: AS & 0,166 & 0,008 & 0,006 & 0,514 & 0,0002 \\
B: AF & 0,007 & 0,002 & 0,81 & 0,003 & 0,037 \\
AB & 0,218 & 0,007 & 0,0009 & 0,001 & 0,051 \\
A^2 & 0,403 & 0,025 & 0,002 & 0,230 & --- \\
B $^{\wedge}$ & 0,012 & 0,004 & 0,24 & 0,001 & --- \\
A $2 B^{\wedge}$ & 0,014 & 0,010 & 0,002 & 0,002 & --- \\
AB $^{\wedge} 2$ & 0,036 & --- & 0,002 & 0,002 & --- \\
A $^{\wedge} 3$ & --- & 0,011 & 0,004 & --- & --- \\
B $^{\wedge} 3$ & --- & --- & 0,003 & --- \\
R-Cuadrado & 0,993 & 0,998 & 0,999 & 0,999 & 0,933 \\
\hline
\end{tabular}

$\mathrm{MA}=309,35+134,48 * \mathrm{AS}-457,55 * \mathrm{AF}-97,47 * \mathrm{AS} * \mathrm{AF}-140,17 * \mathrm{AS}^{2}+208,80 * \mathrm{AF}^{2}+153,50 *$

$\mathrm{AS}^{2} * \mathrm{AF}-94,78 * \mathrm{AS} * \mathrm{AF}^{2}$

$\mathrm{HML}=2,94 \mathrm{X} 10^{5}+4,74 \mathrm{X} 10^{5} * \mathrm{AS}-4,11 \times 10^{5} * \mathrm{AF}-1,33 \mathrm{X} 10^{5} * \mathrm{AS} * \mathrm{AF}-6,14 \mathrm{X} 10^{5} * \mathrm{AS}^{2}+$

$1,31 \mathrm{X} 10^{5} * \mathrm{AF}^{2}+1,04 \mathrm{X} 10^{5} * \mathrm{AS}^{2} * \mathrm{AF}+1,52 \mathrm{X} 10^{5} * \mathrm{AS}^{3}$

$\mathrm{CT}=47,34 * \mathrm{AS}+44,55 * \mathrm{AF}-45,00 * \mathrm{AS} * \mathrm{AF}-66,79 * \mathrm{AS}^{2}-21,55 * \mathrm{AF}^{2}+0,12 * \mathrm{AS}^{2} * \mathrm{AF}+$

$21,87 * \mathrm{AS} * \mathrm{AF}^{2}+21,96 * \mathrm{AS}^{3}$

$\mathrm{CF}=4,35 * \mathrm{AS}+12,25 * \mathrm{AF}-7,27 * \mathrm{AS} * \mathrm{AF}-1,45 * \mathrm{AS}^{2}-11,10 * \mathrm{AF}^{2}+1,90 * \mathrm{AS}^{2} * \mathrm{AF}+1,37 *$

$\mathrm{AS} * \mathrm{AF}^{2}+2,85 * \mathrm{AF}^{3}$

$\mathrm{pH}=4,81-1,89 * \mathrm{AS}-0,96 * \mathrm{AF}+0,52 * \mathrm{AS} * \mathrm{AF}$

\section{Optimización}

Las ecuaciones 1-5, se sometieron a un proceso de optimización buscando minimizar las variables respuestas MA, HM y CF, mientras que el pH se fijó en 3,5, con el objetivo de minimizar los efectos negativos que se puedan tener sobre las características sensoriales del producto. Los resultados predichos y experimentales de la optimización se presentan en la Tabla 6, en la que se observa como los resultados experimentales se corresponden con los predichos por los modelos polinomiales. Los datos en la Tabla 5 señalan que se puede mantener la calidad microbiológica del ensilaje con solo $0,03 \%$ de AS y $1,16 \%$ de AF. 


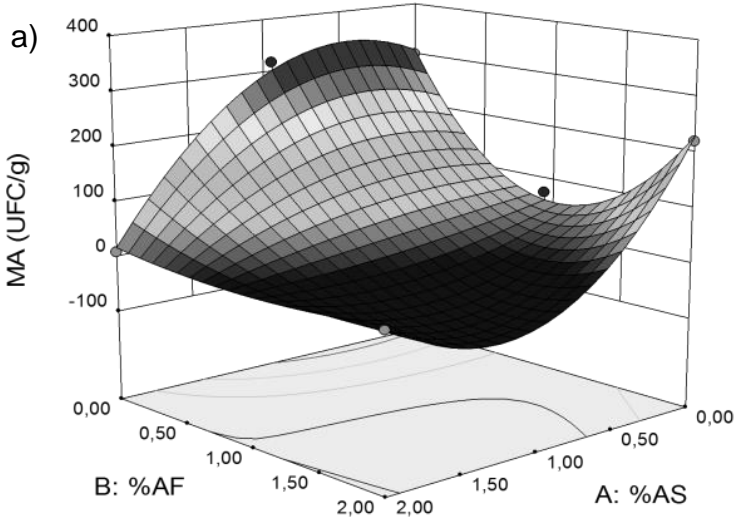

b)

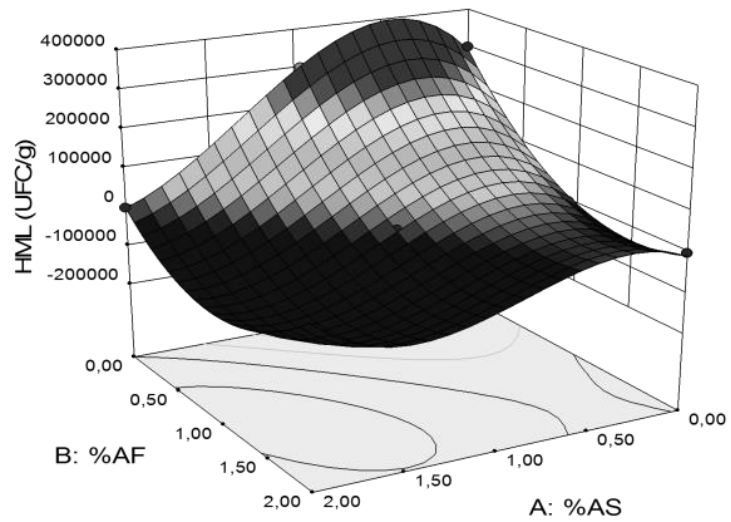

c)

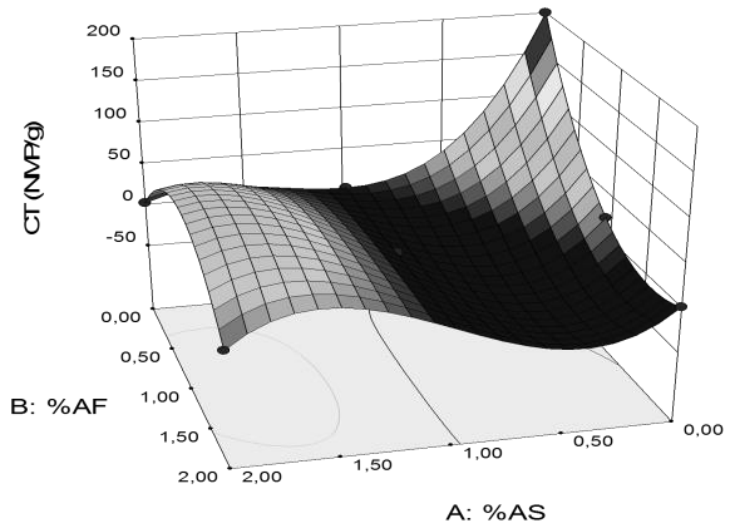

d)
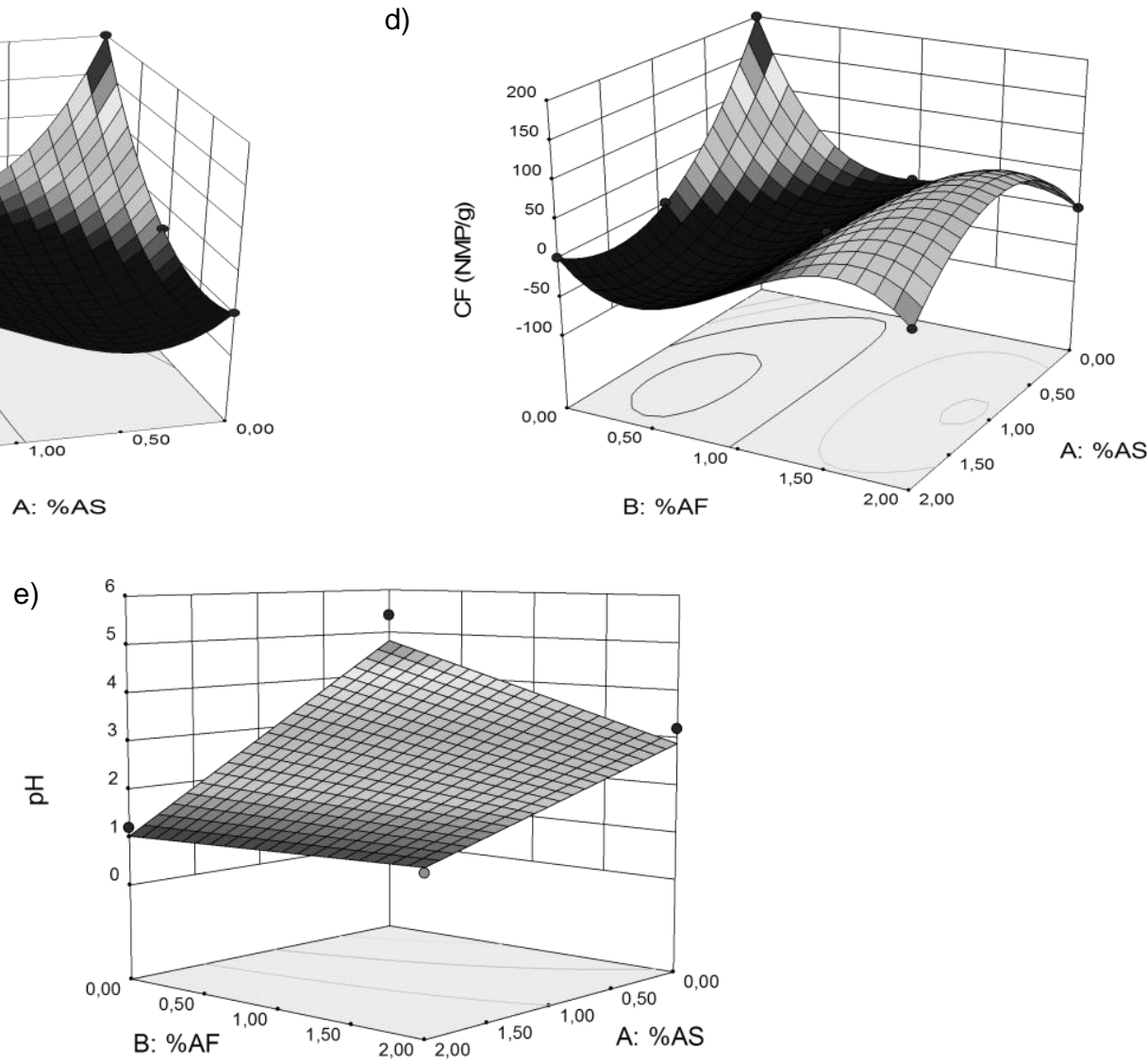

Fig. 1: Efecto del contenido de ácidos sobre los recuentos de: a) mesófilos aerobios (MA) b) hongos y levaduras (HML) c) coliformes totales (CT), d) coliformes fecales (CF) y e) pH, en los ensilados ácidos de vísceras de tilapia roja.

Tabla 5: Resultados predichos y experimentales de la optimización de los modelos para la elaboración de ensilaje.

\begin{tabular}{ccccccccc}
\hline \multicolumn{1}{c}{ Factores } & \multicolumn{7}{c}{ Variables respuestas } \\
\hline & AS (\%) & AF (\%) & $\begin{array}{c}\text { MA } \\
(\mathrm{UFC} / \mathrm{g})\end{array}$ & $\begin{array}{c}\mathrm{HML} \\
(\mathrm{UFC} / \mathrm{g})\end{array}$ & $\begin{array}{c}\mathrm{CT} \\
(\mathrm{NMP} / \mathrm{g})\end{array}$ & $\begin{array}{c}\mathrm{CF} \\
(\mathrm{NMP} / \mathrm{g})\end{array}$ & $\mathrm{pH}$ & Deseabilidad \\
\hline Predicho & 0,03 & 1,16 & 57 & 8 & $<3$ & 10 & 3,66 & 0,93 \\
Experimental & 0,03 & 1,16 & 52 & 10 & $<3$ & $<3$ & 3,39 & \\
\hline
\end{tabular}

Elaboración de alimento balanceado para tilapia en la fase de engorde

La formulación de los alimentos se estandarizó con base en el segundo diseño experimental, del cual se presentan en las Tablas 6 y 7 , las corridas experimentales y el ANOVA, respectivamente. Mientras que en las ecuaciones 6-8 se presentan los modelos ajustados para las tres respuestas, tomando los términos 
estadísticamente significativos y los necesarios para conservar la jerarquía del diseño, con base en lo definido por el ANOVA. Se observa que los modelo de IAA y DE son significativos con un nivel de confianza del $95 \%$, mientras que el de $\mathrm{F}$, solo lo es al $90 \%$ de confianza. Se debe destacar que todos los modelos explican los datos en más de un $90 \%$.

\section{Optimizacion del alimentos balanceado}

Las ecuaciones 6 - 8 se sometieron a un proceso de optimización buscando maximizar $F$ y el contenido de EQD y minimizar el contenido de PV, con el fin de minimizar los costos sin afectar la flotabilidad del alimento, ya que para tilapia roja este es un parámetro de calidad. Además, a pesar de que el PV puede reducir la huella de carbono, tambien puede incrementar el potencial de eutrofización (Smárason et al., 2017). De esta forma este estudio se enmarca en la tendencia actual en la que se han evaluado los efectos de usar mezclas de fuentes agrícolas y marinas para reducir el impacto ambiental que genera la piscícultura y reutilizar fuentes de alimento para hacerla sostenible (Smárason et al., 2017; Ytrestøyl et al., 2015). En la Tabla 8 se presentan los valores máximos predichos 0,4 y 0,6 para PV y EQD, respectivamente. Por su parte los valores de las respuestas obtenidas experimentalmente se corresponden con las predichas, incluso en algunos casos superándolas, lo cual destaca la potencia de la metodología de superficies de respuesta como método de optimización.

Tabla 6: Matriz de experimentos para la formulación de alimentos para tilapia roja a partir de ensilaje químico y pienso vegetal.

\begin{tabular}{cccccc}
\hline Corridas & $\mathrm{PV}(\%)$ & $\mathrm{EQD}(\%)$ & $\mathrm{F}(\mathrm{s})$ & $\mathrm{IAA}(\mathrm{g})$ & $\mathrm{DE}\left(\mathrm{Kg} / \mathrm{m}^{3}\right)$ \\
\hline 1 & 0,55 & 0,45 & 2,00 & 1,47 & 834,63 \\
2 & 0,45 & 0,55 & 2448,33 & 1,26 & 545,41 \\
3 & 0,40 & 0,60 & 1219,67 & 1,32 & 578,24 \\
4 & 0,40 & 0,60 & 1076,00 & 1,43 & 596,21 \\
5 & 0,60 & 0,40 & 2,33 & 1,43 & 751,99 \\
6 & 0,50 & 0,50 & 2,67 & 1,35 & 686,79 \\
\hline
\end{tabular}

Tabla 7: ANOVA de las variables respuestas del diseño de mezclas para en la formulación de un alimento balanceado para tilapia.

\begin{tabular}{lccc}
\hline \multicolumn{4}{c}{ Valor P } \\
\hline Parámetro/Factor & $\mathrm{F}(\mathrm{s})$ & $\mathrm{IAA}(\mathrm{g})$ & $\mathrm{DE}\left(\mathrm{Kg} / \mathrm{m}^{3}\right)$ \\
Modelo & 0,069 & 0,050 & 0,005 \\
$\mathrm{AB}$ & 0,131 & 0,332 & 0,167 \\
$\mathrm{AB}(\mathrm{A}-\mathrm{B})$ & 0,053 & 0,023 & 0,006 \\
$\mathrm{AB}(\mathrm{A}-\mathrm{B})^{2}$ & 0,062 & --- & -- \\
R-Cuadrado $^{2}$ & 0,989 & 0,916 & 0,991 \\
\hline
\end{tabular}

$$
\begin{aligned}
& \log _{10} F=+0,37 * A+3,06 * \mathrm{~B}-12,95 * \mathrm{AB}-9,29 * \mathrm{AB}(\mathrm{A}-\mathrm{B})+31,21 * \mathrm{AB}(\mathrm{A}-\mathrm{B})^{2} \\
& \operatorname{Logit}(\mathrm{IAA})=-1801,26 * \mathrm{~A}+1872,12 * \mathrm{~B}-143,98 * \mathrm{AB}+7665,75 * \mathrm{AB}(\mathrm{A}-\mathrm{B}) \\
& \mathrm{DE}=+752,86 * \mathrm{~A}+587,66 * \mathrm{~B}+86,90 * \mathrm{AB}+1101,94 * \mathrm{AB}(\mathrm{A}-\mathrm{B})
\end{aligned}
$$

El alimento obtenido presenta valores de densidad específica (DE) que estan por debajo de los obtenidos por Pantoja et al. (2011), quienes alcazaron valores entre $649,8-818,85 \mathrm{Kg} / \mathrm{m}^{3}$, trabajando con ensilados biológicos de tilapia roja, para la elaboración de alimento extriudo. Las diferencias en este parámetro, pueden deberse a los niveles de grasa que presenta el alimento en el presente estudio, puesto que en el ensilaje biológico se utiliza melaza que incrementa la densidad. En el presente trabajo, se logró reemplazar una fraccion mayor de ensilaje de visceras con respecto a otros estudios donde utilizaron entre $15 \%$ y $40 \%$, con contenidos de proteina y otros parametros fisicoquimicos similares, en alimentos para tialpia (Llanes et al., 2010), lo cual resulta de interés porque se está máximizando la utilización del ensilado. 
Tabla 8: Resultados predichos y experimentales de la optimización de los modelos para la elaboración de alimento.

\begin{tabular}{ccccccc}
\hline & \multicolumn{2}{c}{ Factores } & \multicolumn{3}{c}{ Variables respuestas } \\
\hline & PV & EQD & F (s) & IAA (g) & DE $\left(\mathrm{Kg} / \mathrm{m}^{3}\right)$ & Deseabilidad \\
\hline Predicho & 0,4 & 0,6 & 1145,6 & 1,4 & 587,6 & 0,74 \\
Experimental & 0,4 & 0,6 & 1029,3 & 1,6 & 597,4 & \\
\hline
\end{tabular}

\section{Análisis de Ciclo de Vida (ACV) del alimento balanceado}

El ACV permitió identificar los impactos potenciales asociados a la elaboración de $1 \mathrm{~kg}$ de alimento con la inclusión de ensilado químico de vísceras de tilapia roja, así como los puntos críticos del proceso de elaboración que mayor aporte presenta sobre las categorías de impacto evaluadas y en los que se deben proponer acciones de mitigación. En la Tabla 9 se presentan los resultados del análisis de categorías de impactos evaluadas, como son la cantidad de emisiones de GEl, consumo de energía y consumo de agua para la elaboración de $1 \mathrm{~kg}$ de alimento con inclusión de ensilado químico. Se identificó que más del $50 \%$ de las emisiones de GEI se dieron durante la etapa del secado (P4) del alimento, seguido de las actividades de extrusión del alimento (P3), transporte de vísceras (P1) y ensilaje (P2), con un 31\%, 11,7\% y 5,6\%, respectivamente.

El aprovechamiento de las vísceras de tilapia roja mediante el ensilaje químico (P2), fue la etapa del proceso de elaboración del alimento que menos aportes hizo a las categorías de impacto evaluadas, sugiriendo así que el ensilaje químico es un sustrato con alto potencial para el aprovechamiento de subproductos piscícolas como materia prima inocua y de buena aceptabilidad para la preparación de alimentos balanceados para peces. Además, es la etapa del proceso de elaboración de las dietas que menos aportó a la emisión de GEI $(5,6 \%)$ y que menos consumo de energía tuvo (1,8\%), por lo que el ensilado de vísceras se presenta como una alternativa para reducir la presión existente sobre la parte comestible del pez (Smárason et al., 2017; Ytrestøyl et al., 2015), lo cual ha sido definido como uno de los aspectos críticos para alcanzar sostenibilidad en la acuicultura intensiva (Pelletier et al., 2009; d'Orbcastel et al., 2009). Por otro lado, el aporte de las emisiones de GEl durante el transporte de las vísceras (P1) fueron del 11,7\%, evidenciando que se debe revisar la logística de recolección de la materia prima, con el objeto de minimizar el número de viajes realizados para su obtención. Comportamiento que se ha reportado en diferentes sistemas de producción acuícola (Samuel-Fitwi et al., 2013). En cuanto al consumo de energía (kW/h), más del $80 \%$ está asociado al secado del alimento (P4), seguido de la extrusión (P3) y el ensilaje de vísceras (P2) con 14\% y 1,8\%, respectivamente.

Tabla 9: Categorías de impactos en la elaboración de dietas para peces con inclusión de EQD.

\begin{tabular}{|c|c|c|c|c|c|}
\hline Etapa & $P 1$ & $P 2$ & P3 & P4 & Total \\
\hline \multicolumn{6}{|c|}{ Potencial de calentamiento global - emisiones GEI $\left(\mathrm{KgCO}_{2} \mathrm{eq}\right)$} \\
\hline & 0,0298 & 0,014 & 0,079 & 0,131 & 0,254 \\
\hline \multicolumn{6}{|c|}{ Consumo de energía (kW/h) } \\
\hline & 0,0000 & 0,010 & 0,079 & 0,480 & 0,569 \\
\hline \multicolumn{6}{|c|}{ Consumo de agua (L) } \\
\hline & 0 & 0,5 & 1,7 & 0,3 & 2,5 \\
\hline \multicolumn{6}{|c|}{ Potencial de eutrofización ( $\mathrm{KgPO}_{4}$ eq) } \\
\hline & 0 & $7,0 \mathrm{E}-07$ & $1,2 \mathrm{E}-07$ & 3,9E-05 & 4,0E-05 \\
\hline \multicolumn{6}{|c|}{ Potencial de Acidificación ( $\mathrm{KgSO}_{2}$ eq) } \\
\hline & $1,0 \mathrm{E}-07$ & $3,8 \mathrm{E}-06$ & $6,3 E-07$ & 8,2E-06 & 1,3E-05 \\
\hline
\end{tabular}

El secado presenta un consumo energético considerable, sin embargo, es fundamental para alcanzar los rangos de humedad y de actividad acuosa del producto, que eviten la proliferación de microorganismos alterantes, trabajando a temperatura moderada para proteger el contenido nutricional del alimento. En este caso se trabajó a $60^{\circ} \mathrm{C} \pm 2^{\circ} \mathrm{C}$ por $12 \mathrm{~h}$, con base en lo reportado por Opstvedt et al. (2003). Los cuales concluyeron que la exposición a altas temperaturas del alimento para peces durante su procesamiento disminuía la digestibilidad de las proteínas por la racemización de los aminoácidos, la formación de puentes disulfuros y las reacciones de Maillard. Es por ello que, al utilizar temperaturas de secado bajas el tiempo de secado en horno se prolonga (12 horas en promedio), aumentando el consumo de energía de la elaboración de las dietas con inclusión de EQD. 
Se ha reportado que las emisiones promedio de GEI asociadas a la elaboración de $1 \mathrm{~kg}$ de alimento deshidratado para salmónidos a partir de residuos de alimentos, fueron de $0,198 \mathrm{KgCO}_{2}$ eq (Ogino et al. 2007), siendo las etapas de producción y de deshidratación del alimento, las que mayores emisiones de este tipo aportaron al sistema, principalmente por el uso de combustibles fósiles (gas natural) durante la elaboración del alimento. Los resultados de Ogino et al., (2007), aunque con las mismas etapas críticas identificadas, son relativamente menores a los obtenidos en el presente estudio. Los cuales, a su vez en cuanto a consumo de energía, potencial de calentamiento global, de acidificación y de eutrofización son similares a los de Papatryphon et al., (2004) $\left(0,81 \mathrm{~kW} / \mathrm{h}, 0,05 \mathrm{KgCO}_{2} \mathrm{eq}, 4 \times 10^{-5} \mathrm{KgSO}_{2}\right.$ eq y $1 \times 10^{-5} \mathrm{KgPO}_{4}$ eq de emisiones, respectivamente), quienes trabajaron en la elaboración de alimentos para salmónidos con alto contenido de harina de pescado, subproductos de pescado, bajo contenido de harina de pescado y proteína vegetal.

Los impactos potenciales de la elaboración del alimento con la inclusión de EQD, expresado en kg de alimento elaborado, son bajos para el potencial de acidificación y eutrofización, pero altos para el consumo de energía y el potencial de calentamiento global, como resultado de la alta demanda energética, principalmente durante la etapa de secado (P4) y extrusión del alimento (P3). Estos importantes impactos de consumo energético ya han sido reportados en cultivos intensivos de trucha (Samuel-Fitwi et al., 2013). Mientras que los bajos potenciales de eutrofización son contrarios a los resultados de Smárason et al., (2017), trabajando en tres dietas diferentes en alimentación de Salvelino del ártico. Quienes afirmaron que el alimento tiene un alto potencial de eutrofización por lo que es el factor más importante a considerar cuando de reducir el impacto ambiental se trata.

Teniendo en cuenta estos resultados en las categorías de impacto evaluadas, el secado de las dietas es un punto crítico en su proceso de elaboración. Pero la etapa de extrusión y secado son necesarias independientemente de que se use ensilado como fuente de proteína. Por lo cual, las estrategias para reducir el impacto ambiental potencial de la elaboración de los alimentos para peces, deben estar enfocadas en la búsqueda de fuentes energía limpias que permitan disminuir el uso de energía eléctrica en esta etapa del proceso.

\section{CONCLUSIONES}

(i) Los recuentos microbiológicos y el pH de los ensilados ácido de vísceras de tilapia roja (Oreochromis spp.) se ven afectados de manera significativa por la concentración de los ácidos sulfúrico y fórmico utilizados en el proceso; (ii) Los contenidos de dichos ácidos pueden ser optimizados para racionalizar su uso sin comprometer la calidad microbiológica del producto obtenido, de forma tal que este pueda ser utilizado como insumo en la elaboración de alimentos para peces; (iii) La inclusión de ensilados químicos como fuente de proteína en las dietas para peces no solo permite cumplir con los requerimientos nutricionales del producto terminado, sino que además tiene efectos positivos sobre el medio ambiente debido a reduce las emisiones de GEl y el consumo de energía.

\section{NOTACIÓN}

$\begin{array}{llll}\% \mathrm{P} & \text { Proteína } & \text { AF } & \text { \% ácido fórmico } \\ \% \mathrm{H} & \text { Humedad } & \mathrm{MA} & \text { Mesófilos aerobios } \\ \% \mathrm{G} & \text { Grasa } & \text { HML } & \text { Hongos, mohos y levaduras } \\ \% \mathrm{C} & \text { Cenizas } & \mathrm{CT} & \text { Coliformes totales } \\ \text { EQ } & \text { Ensilaje químico } & \mathrm{CF} & \text { Coliformes fecales } \\ \text { EQD } & \text { Ensilaje químico desengrasado } & \mathrm{F} & \text { Flotabilidad } \\ \text { A } & \text { Alimentos para peces a partir de ensilaje químico } & \text { IAA } & \text { Índice de absorción de agua } \\ \text { AS } & \% \text { ácido sulfúrico } & \text { DE } & \text { Densidad específica } \\ \text { VT } & \text { Vísceras de tilapia } & \text { PV } & \text { Pienso vegetal } \\ \text { ACV } & \text { análisis de ciclo de vida } & \text { P1 } & \text { la recolección de las vísceras } \\ \text { P2 } & \text { la elaboración del ensilado químico } & \text { P3 } & \text { la preparación de dietas } \\ \text { P4 } & \text { el secado del alimento } & \text { UF } & \text { unidad funcional } \\ \text { GEI } & \text { gases de efecto invernadero } & \text { VDT } & \text { Vísceras de tilapia desengrasadas } \\ \text { PE } & \text { Polietileno } & \text { PP } & \text { Polipropileno }\end{array}$




\section{AGRADECIMIENTOS}

Los autores del presente trabajo agradecen a la estrategia de sostenibilidad del Comité para el Desarrollo de la Investigación en la Universidad de Antioquia (CODI), así mismo a COLCIENCIAS (Proyecto Código 58746) por el apoyo financiero entregado.

\section{REFERENCIAS}

Ainsworth, P., S. Ibanoğlu y otros tres autores, Effect of Brewers Spent Grain Addition and Screw Speed on the Selected Physical and Nutritional Properties of an Extruded Snack, doi: 10.1016/j.jfoodeng.2007.01.004, J. Food Eng., 81(4), 702709 (2007)

AOAC, Official Methods of Analysis of AOAC International, 17 Ed., 2-66, Association of Official Analysis Chemists International, Washington, USA (2000)

Boissy, J., J. Aubin y otros cuatro autores, Environmental Impacts of Plant-Based Salmonid Diets at Feed and Farm Scales, doi: 10.1016/j.aquaculture.2011.08.033, Aquaculture, 321(1-2), 61-70 (2011)

Botello, A., J. Toledo y otros tres autores, Conservación in Vitro de Tres Ensilajes de Pescado (Opisthonema Oglinum) Caracterización Físico-Química, Granma Ciencia, ISSN: 1027-975X, 14(1), 1-15 (2010)

Chalamaiah, M., B. Dinesh y otros dos autores, Fish Protein Hydrolysates: Proximate Composition, Amino Acid Composition, Antioxidant Activities and Applications: A Review, doi: 10.1016/j.foodchem.2012.06.100, Food Chem., 135(4), 3020-3038 (2012)

Dekamin, M., H. Veisi y otros cuatro autores, Life Cycle Assessment for Rainbow Trout (Oncorhynchus mykiss) Production Systems: a Case Study for Iran, doi: 10.1016/j.jclepro.2014.12.006, J. Clean Prod., 91, 43-55 (2015)

Deraz, S., Protein Hydrolysate from Visceral Waste Proteins of Bolti Fish (Tilapia nilotica): Chemical and Nutritional Variations as Affected by Processing pHs and Time of Hydrolysis, J. Aquat. Prod T, ISSN: 1049-8850, 24(6), 614-631 (2015)

d'Orbcastel, R., J. Blancheton y J. Aubin, Towards Environmentally Sustainable Aquaculture: Comparison Between Two Trout Farming Systems Using Life Cycle Assessment, doi:10.1002/9781118496077, Aquacult. Eng., 40(3), 113-119 (2009)

Esquivel, M., La Pesca y la Acuicultura En Colombia - 2014, Asuntos Internacionales AUNAP, Autoridad Nacional de Acuicultura y Pesca - AUNAP, 9-15, Bogotá, Colombia (2014)

Fernández, H., A. Tabera y otros dos autores, Obtención, Caracterización Microbiológica y Fisicoquímica de Ensilado Biológico de Anchoita (Engraulis anchoita), REDVET, ISSN: 1695-7504, 14(2), 1-15 (2013)

Goosen, N., L. de Wet y otros tres autores, Fish Silage Oil From Rainbow Trout Processing Waste Asalternative to Conventional Fish Oil in Formulated Diets Formozambique Tilapia Oreochromis Mossambicus, doi: 10.1016/j.anifeedsci.2013.10.019, Anim. Feed Sci. Tech., 188, 74-84 (2014)

Guinée, J., M. Gorrée y otros doce autores, Handbook on Life Cycle Assessment Operational Guide to the ISO Standards, $7^{a}$ Ed., 255-255, Springer, Dordrecht, Netherlands (2001)

Güllü, K., Ü. Acar y otros dos autores, Replacement of Fish Meal with Fish Processing by-Product Silage in Diets for the Rainbow Trout, Oncorhynchus mykiss, Pak J. Zool., ISSN: 0030-9923, 46(6), 1607-1703 (2014)

Henriksson, P.J.G., J. Guinée y otros dos autores, Life Cycle Assessment of Aquaculture Systems-A Review of Methodologies, doi: 10.1007/s11367-011-0369-4, Int. J. Life Cycle Ass., 17(3), 304-313 (2012)

Llanes, J., J. Toledo y otros tres autores, Digestibilidad Aparente de los Ensilajes de Residuos Pesqueros en Tilapias Rojas (Oreochromis Mossambicus X O. Niloticus), Zootecnia Trop., ISSN: 0798-7269, 28(4), 499-505 (2010)

Ma, H., Z. Pan y otros 5 autores, Properties of Extruded Expandable Breadfruit Products, doi: 10.1016/j.Iwt.2011.09.007, Food Sci. Tech-Brazil, 46(1), 326-334 (2012)

Martínez-Alvarez, O., S. Chamorro y A. Brenes, Protein Hydrolysates from Animal Processing By-Products as a Source of Bioactive Molecules with Interest in Animal Feeding: A Review, doi: 10.1016/j.foodres.2015.04.005, Food Res Int., 73, 204-212 (2015)

Minh, N., Effect of Water Temperature and Time during Tilapia Processing to its Fillet Quality, Int. J. multidiscip. Res, ISSN: 2349-4182, 1(6), 178-184 (2014)

Montgomery, D., Design and Analysis of Experiments, 5ª Ed., John Wiley\&Sons, INC., pp. 427-500, NY, USA (2000)

Ogino, A., A. Ikeguchi y otros cuatro autores, Environmental Impact Evaluation of Feeds Prepared from Food Residues Using Life Cycle Assessment, doi:10.2134/jeq2006.0326, J. Environ. Qual., 36(4), 1061-1068 (2007)

Opstvedt, J., N. Eina y otros cuatro autores, Effect on Protein Digestibility of Different Processing Conditions in the Production of Fish Meal and Fish Feed, doi: 10.1002/jsfa.1396, J. Sci. Food Agric., 83(8), 775-782 (2003)

Pantoja, J., S. Sánchez y J. Hoyos, Obtención de un Alimento Extruido para Tilapia Roja (Oreochromis Spp) Utilizando Ensilaje Biológico de Pescado, Rev. Bio. Agro., ISSN: 1692-3561, 9(2), 178-187 (2011) 
Papatryphon, E., J. Petit, S. Kaushik y H. Van, Environmental Impact Assessment of Salmonid Feeds Using Life Cycle Assessment (LCA), doi: 10.1579/0044-7447-33.6.316, AMBIO, 33(6), 316-323 (2004)

Pelletier, N. L., N.W. Ayer y otros siete autores, Impact Categories for Life Cycle Assessment Research of Seafood Production Systems: Review and Prospectus, DOI: 10.1065/lca2006.09.275, Int. J. Life Cycle Ass., 12(6), 414-421 (2007)

Saadi, S., N. Saari y otros tres autores, Recent Advances in Food Biopeptides: Production, Biological Functionalities and Therapeutic Applications, doi: 10.1016/j.biotechadv.2014.12.003, Biotechnol. Adv., 33(1), 80-116 (2014)

Samuel-Fitwi, B., F. Nagel y otros tres autores, Comparative Life Cycle Assessment (LCA) of Raising Rainbow Trout (Oncorhynchus Mykiss) in Different Production Systems, DOI: 10.1016/j.aquaeng.2012.12.002, Aquacult. Eng., 54, 8592 (2013)

Smárason, B.Ö., O. Ögmundarson y otros tres autores, Life Cycle Assessment of Icelandic Arctic Char Fed Three Different Feed Types, doi: 10.4194/1303-2712-v17_1_10, Turk J. Fish Aquat., 17, 79-90 (2017)

Toledo, J., A. Botello y J. Llanes, Evaluación del Ensilado Químico de Pescado en la Alimentación de Clarias Gariepinus (Burchell, 1822), REDVET, 8(9), 1695-7504 (2007)

Vidotti, R., E. Viegas y D. Carneiro, Amino Acid Composition of Processed Fish Silage Using Different Raw Materials, doi: 10.1016/S0377-8401(03)00056-7, Anim. Feed Sci. Technol., 105(1-4), 199-204 (2003)

Ytrestøyl, T., T. S. Aas y T. Åsgård, Utilisation of Feed Resources In Production of Atlantic Salmon (Salmo salar) in Norway, DOI:10.1016/j.aquaculture.2015.06.023, Aquaculture, 448, 365-374 (2015) 